\title{
A Tobacco necrosis virus $D$ isolate from Olea europaea L.: viral characterization and coat protein sequence analysis
}

\author{
J. M. S. Cardoso ${ }^{1}$, M. R. Félix ${ }^{1,2}$, S. Oliveira ${ }^{1,3}$, and M. I. E. Clara ${ }^{1,2}$ \\ ${ }^{1}$ I.C.A.M. Instituto de Ciências Agrárias Mediterrânicas, Évora, Portugal \\ ${ }^{2}$ Departamento de Sanidade Animal e Vegetal, Universidade de Évora, Évora, Portugal \\ ${ }^{3}$ Departamento de Biologia, Universidade de Évora, Évora, Portugal \\ Received May 12, 2003; accepted December 1, 2003 \\ Published online February 16, 2004 (C) Springer-Verlag 2004
}

Summary. A virus isolated from Olea europaea L. grown in Portugal, was identified as a member of the species Tobacco necrosis virus D (TNV-D, genus Necrovirus, family Tombusviridae), based on the molecular and serological properties of the purified virus particles. The genomic region encoding the coat protein (CP) of this isolate (named GP isolate) was amplified by RT-PCR and the cDNA was cloned and sequenced. The CP gene encodes a predicted protein of 269 amino acids showing high identity $(86.2 \%)$ to TNV-D coat protein sequence. Phylogenetic analysis based on necroviruses CP sequences, confirmed GP as a TNV-D isolate. The alignment with homologous TNV-D CP sequences revealed four conserved amino acids involved in $\mathrm{Ca}^{2+}$ binding as well as the plant virus icosahedral capsid protein " $S$ " signature. Based on the determined nucleotide sequence, specific primers were designed and successfully used in RT-PCR for virus diagnosis in naturally infected olive trees.

\section{Introduction}

Tobacco necrosis virus $D$ (TNV-D) is a small icosahedral virus ca. $28 \mathrm{~nm}$ in diameter with a single stranded positive-sense RNA genome approximately $3.8 \mathrm{~kb}$ long [6, 34]. It belongs to the genus Necrovirus [27] and is naturally transmitted by the soil inhabiting fungus Olpidium brassicae (Wor.) Dang [32].

Strains of TNV have been grouped into two distinct species, TNV-A and TNV$\mathrm{D}[2,34]$. The complete nucleotide sequences of TNV-A and TNV-D were reported by Meulewaeter et al. (1990) and Coutts et al. (1991) respectively. A similar genome organization of these two species has been deduced from the determined

Note: Nucleotide sequence data reported is available in the GenBank database under the accession number AY263376. 